\title{
A POLÍTICA EXTERNA BRASILEIRA NO CONFLITO DO CENEPA: atores e instrumentos
}

\author{
Cristian Daniel Valdivieso ${ }^{1}$
}

\begin{abstract}
Resumo
O presente artigo busca refletir sobre como os delineamentos da política externa brasileira foram instrumentalizados no problema das fronteiras entre Equador e Peru, também conhecido como Conflito do Cenepa. O foco analítico concentra-se na política externa da década de 1990, com ênfase na gestão do ex-presidente Fernando Henrique Cardoso (FHC) 1995-2003, que foi quem acompanhou o processo de resolução do embate armado e liderou o caminho para a negociação e consolidação de uma paz duradoura entre as partes envolvidas. O trabalho se desenvolve através de uma abordagem qualitativa. Como instrumentos metodológicos, emprega-se a análise documental de fontes primárias e análise bibliográfica, como recurso para as fontes secundárias. Percebe-se que o apoio da diplomacia brasileira para a resolução do conflito passa pelo interesse em reinventar suas abordagens com relação à região sul-americana, priorizando os temas da agenda internacional do fim da Guerra Fria com preocupações sobre paz, defesa, direitos humanos, integração e resolução de conflitos.
\end{abstract}

Palavras chave: política externa brasileira; FHC; Equador; Peru.

\begin{abstract}
This article seeks to reflect on how the outlines of brazilian foreign policy were instrumentalized in the border problem between Ecuador and Peru, also known as Cenepa Conflict. For this purpose, the analytical focus concentrates on the foreign policy of the 1990s, with emphasis on the management of former President Fernando Henrique Cardoso (FHC) 1995-2003, who accompanied the process of resolving the armed conflict and led the path for the negotiation and consolidation of a durable peace between the parties involved. The work is developed through a qualitative approach and, as methodological instruments, the documentary analysis of primary sources and bibliographic analysis is used as a resource for secondary sources. It is perceived that the brazilian diplomacy support for the resolution of the armed conflict involves the interest in reinventing its approaches in relation to the South American region, prioritizing the topics of the international agenda of the end of the Cold War with concerns about: peace, defense, human rights, integration and conflict resolution.
\end{abstract}

\footnotetext{
${ }^{1}$ Mestrando do programa de Pós-graduação em Relações Internacionais San Tiago Dantas (UNESP-UNICAMP-PUC SÃO PAULO) e graduado em Relações Internacionais pela Universidade Federal da Integração Latino-Americana (UNILA). Membro colaborador do Núcleo de Estudos para a Paz (NEP) e membro do Grupo de Estudos de Defesa e Segurança Internacional (GEDES).
} 
Keywords: Brazilian foreign policy; FHC; Ecuador; Peru. 


\section{Introdução}

A década de 1990 é considerada um marco histórico nas diversas esferas que conformam a arena internacional. Em termos políticos, económicos, sociais, de regionalização, o final do século XX trouxe notáveis mudanças e criou uma série de adaptações para muitos Estados, especialmente os subdesenvolvidos. Um dos âmbitos relevantes, até o momento atual (2018), tem sido o da cooperação para a paz, forjado através da Organização das Nações Unidas (ONU), em cujo Art. 1, da carta² fundadora da instituição, consta como principal objetivo manter a paz e a segurança internacionais (NAÇÕES UNIDAS, 1945). Portanto, considera-se a ONU como uma das principais plataformas para a inserção internacional.

Um fenômeno marcante, como decorrência do fim do conflito bipolar entre os Estados Unidos e a União Soviética, é a globalização, que tem se constituído como o marco de convergência entre práticas políticas e valores inspirados pelos Estados Unidos, como país dominante do cenário global. Dessa junção emergem cuidados com a democracia, direitos humanos, liberalização econômica, integração financeira global e preocupação com fenômenos transnacionais (destacam-se as "novas ameaças"”) (LAMPREIA, 1998, p. 6; ROJAS-ARAVENA, 1993, p. 2).

Em decorrência de um mundo profundamente interconectado, manifestou-se também a divisão espacial por regiões, com o surgimento de blocos regionais de caráter político-econômico como o Mercosul ${ }^{4}, \mathrm{ALCA}^{5}$, $\mathrm{NAFTA}^{6}$, e inquietações paralelas com relação à ampliação do Conselho de Segurança das Nações Unidas (CSNU), em busca de uma maior participação por parte de países em desenvolvimento naquele espaço político que concentra um poder datado desde 1945 (ARRAES, 2005, p. 2).

Nesse contexto, o Brasil da década de 1990, da gestão de Fernando Collor de Mello 1990-1992, experimentou um breve retorno à política externa de alinhamento ${ }^{7}$ aos Estados Unidos. E foi nesse ínterim que as práticas de política externa brasileira se

\footnotetext{
${ }^{2}$ Carta de São Francisco, também conhecida como Carta da ONU.

${ }^{3}$ Algumas das consideradas novas ameaças são: terrorismo internacional; narco-atividades; tráfico ilegal de armas; degradação do meio ambiente; crime organizado internacional; fundamentalismo religioso (LOPEZ, 2003, p. 83-84).

${ }^{4}$ Mercado Comum do Sul.

5 Área de Livre Comércio das Américas.

${ }^{6}$ Associação de Livre Comércio da América do Norte.

${ }^{7}$ Maria Regina Soares de Lima interpreta esta dinâmica de alinhamento como "o paradigma da aliança com Estados Unidos" (LIMA, 1994, p. 40).
} 
materializaram no aproveitamento de acontecimentos conjunturais, como foi o conflito entre Equador e Peru.

O presente trabalho reflete sobre os delineamentos de política externa, estabelecidos no governo do Fernando Henrique Cardoso, como um instrumento que acionou de forma efetiva a diplomacia para apoiar uma resolução da disputa por fronteiras entre os países andinos, em 1995.

Com a finalidade de atingir os objetivos do trabalho, formularam-se duas questões: quais foram os principais atores da diplomacia brasileira que acompanharam a superação do conflito? Que mecanismos foram pensados e empregados pela política externa brasileira para a resolução do embate? A abordagem é qualitativa e alia análise documental, para fontes primárias, à análise bibliográfica, para as secundárias.

Finalmente, o artigo se divide em três partes. A primeira aborda o contexto no qual foi pensada e formulada a política externa brasileira, desde o final do governo José Sarney até Fernando Henrique Cardoso. A segunda parte versa sobre as origens dos diversos conflitos entre Equador e Peru, ao longo da história, para chegar ao ano de 1995, com o conflito armado interestatal. Por fim, analisa-se o processo de resolução do embate, identificando a ação diplomática brasileira no período 1995-1998.

\section{Política externa brasileira na década de 1990: existe um novo paradigma?}

A análise da política externa através de paradigmas é um caminho recorrente na identificação de práticas e dinâmicas que permitem caracterizar as ações do Estado em um período específico de tempo. Existem dois paradigmas amplamente invocados no Brasil quando se fala da política externa no século XX. Esses dois são: o americanista e o globalista (LACERDA, NÓBREGA, 2015, p. 127).

No marco do americanismo, também conhecido como alinhamento ou aliança especial, existiram três momentos em que os Estados Unidos foram vistos como aliados preferenciais: 1945-1964-1990. De acordo com Lima (1994, p. 40), em 1945, o alinhamento ocorreu quando, no governo de Getúlio Vargas, os grupos internos liberais e nacionalistas optaram pela aproximação dos Estados Unidos. Com a aliança em favor de ideais nacional-desenvolvimentistas, criou-se a Usina Volta Redonda, no Rio de Janeiro, com financiamento estadunidense e brasileiro (LIMA, 2006, p. 41). Também foi 
estruturada a Comissão Mista Brasil-Estados Unidos que visava abrir caminhos para o desenvolvimento econômico do país, a via da industrialização (FGV, 2018).

Por sua vez, o paradigma globalista emergiu na década de 1950, tendo como objetivo confrontar o americanismo, entendendo que "a diversificação das relações internacionais do Brasil aumentaria o poder de barganha político e econômico do país junto aos demais Estados, inclusive os Estados Unidos" (SARAIVA, VALENÇA, 2012, p. 10). Lima (1994, p. 35) argumenta que o paradigma se alimentou de visões cepalinas ${ }^{8}$, da relação centro-periferia, o que também contribuiu para a consolidação de uma identidade latino-americana.

O segundo momento do alinhamento ocorreu em 1964, com o golpe militar. Na época, o poder político se concentrou em grupos de interesse ortodoxos, em termos econômicos. $\mathrm{O}$ alinhamento com os Estados Unidos legitimava a postura ideológica com relação à disputa Leste-Oeste e restabelecia a confiança para o ingresso de capital estadunidense no país, assim como dos organismos financeiros internacionais (LIMA, 1994, p. 41).

Já a partir do governo Costa e Silva 1967-1969, os delineamentos da política externa começaram a tomar outros rumos devido ao controle e a autonomia do Itamaraty. Com Geisel 1974-1979, a situação industrial do país, no seu estágio final da substituição de importações e uma forte promoção das exportações, fizeram com que o paradigma globalista se estabelecesse como hegemônico nas relações internacionais do país. Assim, entre a diversidade de parceiros encontraram-se países europeus, asiáticos, terceiro mundistas, africanos e do Oriente Médio (LIMA, 1994, p. 37).

A transição para o governo civil com Sarney, em 1985, permitiu a junção de interesses latino-americanos. Entre as ações relevantes desse governo, destaca-se o restabelecimento de relações com Cuba, a intensificação do comércio com a China e a manutenção do apoio ao Grupo de Contadora ${ }^{9}$ na América Central. Isso evidencia que "quanto mais se estreitavam as possibilidades de atuação do Brasil no plano global, mais

\footnotetext{
${ }^{8}$ Refere-se à Comissão Econômica para América Latina (CEPAL), que teve como pilar o pensamento de Raúl Prebisch.

${ }^{9}$ Grupo formado em janeiro de 1983 por Colômbia, México, Panamá e Venezuela para negociar a crise no istmo centro-americano, que era cenário de uma luta no marco geopolítico bipolar. Ver (PÁEZ, 2013).
} 
a América do Sul foi valorizada como alternativa estratégica, tendo seu eixo centrado na cooperação e integração com a Argentina" (VIZENTINI, 1999, p. 150-151).

Em 1985, o presidente Sarney, junto com o mandatário da Argentina, Raúl Alfonsín, assinaram a Declaração do Iguaçu com a finalidade de desenvolver políticas comuns para introduzir a América do Sul como um ator global. Produto desse interesse regional, em 1988, foi assinado o Tratado de Integração, Cooperação e Desenvolvimento Brasil-Argentina que, finalmente, em 1991, desembocou no Tratado de Assunção dando origem ao Mercosul (VIZENTINI, 1999, p. 151). Através dessa plataforma, já no período Collor, o Brasil se projetou internacionalmente com a etiqueta de global trader, atuando em diversas frentes e procurando se constituir como um global player (MELLO, 2002, p. 38-39).

Como se evidencia, o período da democratização foi chave para a promoção de processos de cooperação no eixo regional. Tudo isso indica que, na década de 1990, presenciou-se uma nova dinâmica, uma atuação com base no "universalismo" das relações brasileiras, que ia além de diversificar as dinâmicas externas e priorizava a ideia de incorporar um enfoque regionalista (VIGEVANI; OLIVEIRA; CINTRA, 2003, p. 35). Embora o triunfo da democracia-liberal norte-americana abrisse caminho para retomar estratégias do passado, “a convergência de valores e as razões pragmáticas do Poder Executivo para retomar o paradigma da aliança especial, não tinham contrapartida no plano dos valores e dos interesses das forças políticas e sociais internas relevantes" (LIMA, 1994, p. 42).

Com Fernando Collor (1990-1992) acontece o terceiro momento do alinhamento. A política externa considerou uma reaproximação ao paradigma tutelar dos Estados Unidos através da implementação de medidas neoliberais. O desconforto interno incrementou, por motivo da incorporação das exigências do Fundo Monetário Internacional (FMI) e do Banco Mundial (BM), o que levou à implementação de reformas ministeriais, especialmente, do Itamaraty. Sob o mando de Celso Lafer, a instituição readquiriu sua autoridade em temas de política externa e, através de uma "adaptação criativa", diminuiu a centralidade com relação à cartilha dos Estados Unidos (FONSECA, 2011, p. 36).

Para Lima (1994, p. 42), no breve período de Fernando Collor e o posterior governo do Itamar, o paradigma globalista tinha-se enfraquecido, o que indicava uma 
postura de carácter "universalista". Por seu lado, Vizentini (2005, p. 383) mantém uma postura, diferente de Lima (1994), argumentando que, mesmo indefinida, "a política externa brasileira indicava uma orientação globalista e uma melhora contínua no relacionamento com os EUA". Seguidamente, assinala que as medidas tomadas ao longo da década de 1990 representaram a "aceitação das demandas das grandes potencias", ou seja, o Brasil estava aceitando as regras (VIZENTINI, 2005, p. 384; MELLO, 2010, p. 78).

Já na administração de FHC (1995-2003), Luiz Amado Cervo (2002) confirma a tese postulada por Vigevani, Oliveira e Cintra (2003, p. 32) de que a gestão de Cardoso foi nutrida com ideias advindas do governo Collor. Quer seja pela atuação do FHC como ministro das Relações Exteriores no período de outubro de 1992 a maio de 1993 (VIZENTINI, 2005, p. 383) ou pela concordância com as políticas de Itamar Franco, quem lançou a proposta para criar a Área de Livre Comércio Sul-Americana (ALCSA) (CERVO, 2002, p. 27). Foi, também, a partir dessa proposta - atuando de forma discreta, mas incisiva contra os interesses estadunidenses de agregar países sul-americanos ao NAFTA - que passou a se pensar a região como América do Sul e não mais como América Latina (CERVO, 2002, p. 27; MELLO, 2002, p. 39; VIZENTINI, 2005, p. 383). Pois, o Brasil fez sacrifícios de autonomia a favor da integração ao aderir tratados como: Regime de Controle de Tecnologia de Mísseis (1995); Tratado de Proibição Completa de Testes Nucleares (1997); Tratado de Não Proliferação Nuclear (1998), o que significou que o país "renunciou ao direito de fazer a bomba atômica" (LAMPREIA, 1998, p. 1213).

Entre outros temas que merecem destaque para a região sul-americana, em 1986, foi estabelecida a Zona de Paz e Cooperação do Atlântico Sul (ZOPACAS) para tratar assuntos correspondentes à segurança do Atlântico Sul (MINISTERIO RELAÇÕES EXTERIORES, 2018). Nesse ínterim, aconteceram situações importantes como a Comissão de Segurança Hemisférica da Organização de Estados Americanos (OEA) e os encontros de ministros da Defesa a partir de 1995, que serviram como marco para a definição da ação contra fenômenos transnacionais (MIYAMOTO, 2008, p. 370).

No âmbito global, promoveu-se a participação do Brasil na ONU. Sua atuação, na década de 1990, girou em torno ao objetivo de mostrar uma inserção competitiva no sistema internacional através da busca de um assento permanente no CSNU (MARTINS, 
2006, p. 36). Desse modo, as operações de paz se constituíram em um instrumento prioritário. A inserção estratégica do Brasil deu a oportunidade de engajamentos profundos em compromissos como a Missão de Verificação das Nações Unidas em Angola (UNAVEM), que iniciou no ano de 1988, já tendo o Brasil como um dos primeiros colaboradores (MINISTÉRIO DA DEFESA, 2018). Arranjos dessa magnitude mostraram a imagem do país como um líder na região e permitiram que atuasse em função da paz regional, como foi no caso do conflito entre Equador e Peru, em 1995.

\section{Perspectiva histórica das relações conflituosas entre Equador e Peru}

A história da vizinhança sul-americana se encontra permeada por conflitos interestatais. Foi através do recurso da guerra que se estabeleceram as fronteiras e foram se definindo as identidades na região (MOREIRA, QUINTEROS, SILVA, 2010, p. 8). Entre os conflitos de maior envergadura se destacam a Guerra da Tríplice Aliança 18641870, a Guerra do Golfo 1879-1883, Guerra do Chaco 1932-1935 e o conflito entre Equador e Peru 1941, 1981, 1995.

O último conflito entre os países andinos, anteriormente mencionados, data de uma longa história de indefinições territoriais, produto do período colonial, que passou pela existência de fronteiras não delimitadas (MONCAYO, 2011, p. 18). Como resultado dessa carência de localização territorial, reinvindicações pelo domínio do espaço nacional emergiram com o surgimento das repúblicas independentes. O Peru conquistou sua independência em 1821, e o Equador, um ano depois. Não obstante, o ideário bolivariano de união americana fez com que o Equador independente aderisse ao Estado denominado Grã-Colômbia ${ }^{10}$.

No ano de 1829, a nação grã-colombiana entrou em guerra com o vizinho peruano, pois o Peru reivindicava territórios amazônicos. $\mathrm{O}$ embate teve como resultado a vitória grã-colombiana. Assinou-se o Tratado de Guayaquil e, posteriormente, o Protocolo Pedemonte-Mosquera, que definia os territórios correspondentes a cada um dos Estados. Contudo, em 1830, a Grã Colômbia se dissolveu, e o Equador foi o herdeiro dos territórios que tinham sido disputados com o Peru (VALENCIA, 1993, p. 12).

${ }^{10}$ Formada pela constituição de 1821 contemplou a dimensão geográfica territorial dos atuais Estados: Colômbia, Equador, Venezuela e Panamá (BLANCO, 2007, p. 72). 
A reação imediata do Peru foi a rejeição e até mesmo a negação da existência do Protocolo (KRIEG, 1986, p. 25). A partir desse momento, começaram a manifestar-se hostilidades entre as partes. Em 1941, o Peru invadiu o território equatoriano (CARRIÓN, 2008, p. 30; GALASTRI, 2005, p. 19; IZURIETA, 2011, p. 11), gerando preocupações regionais e levando aos adversários a assinar um documento que pretendia constituir uma paz duradoura (BIATO, 1999, p. 241). O Protocolo de Rio de Janeiro, de 1942, foi o documento que estabeleceu a paz, mesmo que frágil, entre as partes, favorecendo o Peru na posse dos territórios amazônicos que o país reivindicava desde o confronto com a Grã Colômbia (PÉREZ, 1992, p. 19).

Durante a demarcação territorial, em 1947, o Serviço Aero-fotométrico dos Estados Unidos constatou a existência de um rio, denominado Cenepa, que alterava o desenho da delimitação especificada no Protocolo de Rio de Janeiro e gerava discrepâncias entre a realidade geográfica e o texto (BIATO, 1999, p. 241; PÉREZ, 1992, p. 20). Essa evidencia catapultou a rejeição equatoriana do documento, considerando-o inexecutável. Anteriormente, o Equador já avaliava aquele tratado como inválido, pois, mesmo reconhecendo que o Peru tinha invadido a jurisdição equatoriana, o Protocolo concedia o território ao invasor. A evidencia que sustentava o argumento equatoriano era que no Art. II do documento consta que "o Governo do Peru retirará dentro do prazo de 15 dias, a contar desde essa data, suas forças militares até a linha descrita no art. VIII deste Protocolo" (PROTOCOLO DE RIO DE JANEIRO, 1942). Com base nesse artigo, o Equador considerava inválido o protocolo por legitimar a invasão peruana.

O problema em torno ao protocolo deixou um espaço perigoso de "78 km" sem demarcação (BATISTA, 2005, p. 129; MARCELLA, 2000; MARES; PALMER, 2012, p. 59; ORTEGA, 2011, p. 101). Como consequência da falta de acordo entre as partes, um novo conflito emergiu no ano de 1981, na região de Paquisha. Nessa ocasião, o Peru atuou em função de uma suposta infiltração equatoriana no seu território (NOVAK; NAMINHAS, 2010, p. 12). A resposta equatoriana foi a solicitação de uma reunião urgente do Conselho Permanente da OEA, encaminhada pelo embaixador equatoriano, Raúl Falconí, denunciando os ataques (MONCAYO, 2011, p. 54). Em vista da ameaça 
de uma guerra generalizada, o grupo dos Países Garantes $^{11}$ se declarou em sessão permanente conseguindo dar fim aos confrontos armados, mas sem instaurar diálogos produtivos para a consolidação da paz (MONCAYO, 2011, p. 56-57).

Na década de 1990, o ex-presidente equatoriano Rodrigo Borja (1988-1992) tentou renovar as relações entre as partes em conflito, solicitando uma arbitragem papal, no marco da Assembleia Geral das Nações Unidas, em 1991. A resposta peruana foi uma carta do ex-presidente Alberto Fujimori, sugerindo a aceitação de quatro pontos para terminar com o conflito (PRADO, 1993, p. 70): (1) concluir a demarcação paralisada em 1947, fechando os $78 \mathrm{~km}$ restantes; (2) cumprir com o Art. IV do protocolo sobre a subscrição de um tratado de comércio e navegação ${ }^{12}$ que outorgaria ao Equador livre acesso portuário; (3) criação de um acordo de integração fronteiriça; (4) acordo de medidas de fomento e confiança mútua e segurança entre Equador e Peru (PRADO, 1993, p. 70).

A proposta do ex-presidente peruano contrariou diretamente os interesses equatorianos porque representava, implicitamente, a aceitação do Protocolo de Rio de Janeiro, que o Equador por anos denunciava como inválido e inexecutável. Foi assim que os avanços na consolidação da paz permaneceram congelados pela falta de entendimento. O revanchismo fez com que as partes rejeitassem qualquer proposta e alternativa de solução. Essas atitudes guiaram a ambos Estados ao aprofundamento das hostilidades, desembocando no conflito do Cenepa, em 1995.

\section{O conflito do Cenepa: a atuação brasileira pela paz regional}

O embate de 1995 é também conhecido com o nome da localidade onde aconteceu o confronto armado, a região do Cenepa. A disputa sobreveio entre os dias 26 de janeiro e 28 de março, mas o estabelecimento da paz ocorreu só no ano de 1998, com a assinatura da Ata Presidencial de Brasília. A culminação do processo bélico entre Equador e Peru esteve atrelada a uma série de fatores, entre os quais podemos encontrar: a participação

11 O grupo dos Países Garantes foi conformado por Argentina, Brasil, Chile e os Estados Unidos que atuaram como formuladores do Protocolo do Rio de Janeiro de 1942 e acompanharam o cumprimento dos artículos especificados nesse tratado (PROTOCOLO DE RIO DE JANEIRO, 1942).

${ }^{12}$ Essa proposta tinha como objetivo que o Equador se conformasse com a livre navegação e assim fechar a porta às reivindicações territoriais. Pois, durante o conflito de Paquisha, o ex-presidente equatoriano Jaime Roldós Aguilera alimentava a ideia de Equador como país amazônico (ROLDÓS, 1981). 
dos Países Garantes; a implementação de uma operação de manutenção da paz; e a promoção do diálogo por meio das negociações.

Inicialmente, foram colocadas duas perguntas com a finalidade de guiar o trabalho para o objetivo de refletir sobre as medidas propostas pela política externa brasileira ao longo do conflito até sua resolução. As questões são: quais foram os principais atores da diplomacia brasileira que acompanharam a superação do conflito? Que mecanismos foram pensados e empregados pela política externa brasileira para a resolução do problema?

Para responder à primeira pergunta é pertinente voltar à assinatura do Protocolo do Rio de Janeiro, de 1942. No Art. V do documento consta que "a gestão dos Estados Unidos, Argentina, Brasil e Chile continuará até a demarcação definitiva das fronteiras entre o Peru e o Equador, ficando este Protocolo e sua execução sob a garantia dos quatro países citados" (PROTOCOLO DE RIO DE JANEIRO, 1942). A participação dos Estados Unidos era limitada devido a seu envolvimento na Segunda Guerra Mundial. Como foi analisado na primeira seção do artigo, na década de 1940, com Getúlio Vargas, predominou o paradigma da aliança especial ou alinhamento. Essa condição de aliados e a conjuntura internacional da guerra permitiram que o Brasil liderasse o processo de paz entre Equador e Peru, como articulador principal na região.

Oswaldo Aranha foi o diplomata brasileiro nomeado pelos Países Garantes para dar continuidade e agilizar a demarcação da fronteira. Para isso, foi solicitada a participação do Capitão de Mar e Guerra Braz Dias de Aguiar, pela sua experiência em demarcação de fronteiras, tendo atuado na presidência da Comissão Demarcadora da Fronteira entre Peru e Bolívia. Não obstante, o laudo emitido pelo capitão discordava da realidade geográfica (GALASTRI, 2005, p. 21). Foi assim que, como se argumentou anteriormente, o Equador se negou a continuar a demarcação com base no Protocolo. (BIATO, 1999, p. 243).

A participação brasileira foi proeminente, desde 1942, mesmo que o laudo do capitão não tenha concordado com a situação territorial real. Já em 1995, essa participação foi mais proativa no sentido de emitir propostas para a consolidação da paz. Contudo, entre 1941 e 1995, existe um lapso temporal de 51 anos nos quais o conflito se manteve inativo, mas latente. Pode-se inferir que esses anos são produto, em alguma medida, da carência de incentivos para a negociação da paz e da falta de compromisso dos Países 
Garantes com relação ao Art. V, anteriormente citado. O mesmo poderia ser argumentado com relação à OEA, cujas ações foram limitadas. Carrión (2008, p. 117) analisa a participação da organização considerando que o ex-presidente colombiano César Gaviria, secretário geral no período 1994-2004, trabalhou a labor de bons ofícios, mas que na realidade resultaram em "só bons desejos".

No plano efetivo, em 1995, a ação dos Países Garantes se destacou devido à criativa proposta formulada a partir da Declaração de Paz do Itamaraty. No tratado, assinado pelas partes no dia 17 de fevereiro, consta, como primeiro ponto, o envio de uma missão de observadores militares para separar as tropas equatorianas e peruanas; criar uma zona desmilitarizada; mobilizar os contingentes para seus respectivos países; e criar o ambiente adequado para o início das conversações relativas à paz (DECLARAÇÃO DE ITAMARATY, 1995). Essa operação de carácter multilateral teve como nome Missão de Observadores Militares Equador-Peru (MOMEP) ${ }^{13}$.

O processo de diálogos de paz durou aproximadamente três anos e resultou na assinatura de diversos acordos complementares, a saber: Declaração de Montevidéu, de 28 de fevereiro de 1995 (agradecimento à participação dos Países Garantes e compromisso das partes em manter a paz); Acordo de Quito, de 23 de fevereiro de 1996 (chanceler brasileiro Luiz Felipe Lampreia entrega a lista dos impasses ${ }^{14}$ para iniciar as negociações); Comunicado de Buenos Aires, de 19 de junho de 1996 (define-se a cidade de Brasília como a sede das negociações); e Acordo de Santiago, de 29 de outubro de 1996 (articulam-se os procedimentos para garantir a busca de uma solução global dos impasses territoriais) (PRADO, 2003, p. 117).

A atuação brasileira, tanto na liderança militar da MOMEP como nas negociações, foi imprescindível, mas a estratégia tomou direções diversas conforme os diálogos diplomáticos foram bloqueados pelos desentendimentos entre Equador e Peru. Evidência disso é que, em 1998, como consequência da paralização das negociações, as partes em conflito decidiram dirigir uma carta ao então presidente do Brasil, Fernando Henrique

\footnotetext{
${ }^{13}$ A colaboração brasileira total na operação articulou a participação de 191 militares (MINISTÉRIO DA DEFESA, 2018). Já no final da operação destacasse a atuação de 134 indivíduos entre civis e militares: 14 militares da Argentina; 1 civil e 53 militares brasileiros; 5 civis e 19 militares dos Estados Unidos; 11 militares do Chile; 13 civis e 9 militares equatorianos; e 9 militares do Peru (RECASENS, 2000, p. 6).

${ }^{14}$ Foram um total de seis impasses: (1) linhas geodésicas-rio Napo; (2) setor Lagartococha-Guepi; (3) Zarumilla; (4) Cusumaza-Bumbuisa/Santiago; (5) hitos Conhuime Sur-20 de Noviembre; (6) inexecutavilidade/acesso ao Amazonas. Para saber mais ver (ACUERDO DE SANTIAGO, 1996).
} 
Cardoso, também coordenador dos Países Garantes (LAMPREIA, 1998, p. 14). O comunicado invocava o Art. VII do Protocolo de Rio de Janeiro, de 1942, e o ponto quatro do Acordo de Santiago, de 1996, que sugerem que frente a qualquer desacordo os Garantes têm a capacidade de propor procedimentos adequados para a resolução das diferenças e dar continuidade ao processo de paz (PROTOCOLO DE RIO DE JANEIRO, 1942; ACUERDO DE SANTIAGO, 1996).

Neste ponto, cabe desenvolver uma análise do raciocínio dos presidentes das partes em disputa e do presidente do Brasil como líder dos Garantes. A mediação do conflito, ao longo das negociações ${ }^{15}$, teve como resultado a criação de um documento denominado Reflexiones, subscrito no dia 26 de novembro de 1997. O documento coincidia com a proposta feita por Fujimori no ano de 1991, como contra-argumento à arbitragem papal solicitada pelo ex-presidente equatoriano, Rodrigo Borja (MONCAYO, 2011, p. 398-399). Em vista das similitudes dos documentos, os negociadores equatorianos não aceitaram os juízos emitidos pelas comissões sobre os impasses, já que consideravam a existência de benefícios maiores para o Peru.

Os constantes desentendimentos no processo de paz guiaram os presidentes, equatoriano e peruano, a tomar a via da diplomacia presidencial. Fujimori, que tinha acompanhado o processo por quase dez anos, dialogou com seu homólogo equatoriano Jamil Mahuad, recém-eleito ${ }^{16}$, em 1998. O resultado do exercício da diplomacia presidencial desembocou na carta enviada ao presidente do Brasil, argumentando:

\footnotetext{
"Embora os esforços feitos pelas Comissões Binacionais, as Chancelarias e pessoalmente por nós [os presidentes do Equador e Peru] [...], não tem sido possível encontrar uma fórmula mutuamente aceitável para culminar a fixação no território da fronteira" (CARTA DE LOS PRESIDENTES, 1998).
}

\footnotetext{
15 Estabeleceram-se um total de sete rondas de negociação e criaram-se comissões, conformadas pelas partes em disputa e representantes dos países garantes, para o tratamento dos impasses fronteiriços (MONCAYO, 2011, p. 402).

${ }^{16} \mathrm{Na}$ década de 1990 o Peru teve um único presidente, Alberto Fujimori. Pela sua parte, o Equador, teve diversos presidentes que acompanharam o conflito: Sixto Duram Ballén (1992-1996), Abdalá Bucaram (1996-1997), Fabián Alarcón (1997-1998), Jamil Mahuad (1998-2000).
} 
Na gestão FHC, a diplomacia presidencial ${ }^{17}$ foi um recurso amplamente utilizado para reconstruir a imagem brasileira externamente. A atuação, vinculada ao sucesso do Plano Real ${ }^{18}$, permitiu uma participação firme em foros e diálogos multilaterais e tendo o presidente como autoridade máxima no âmbito internacional (CERVO, 2002, p. 10; LAMPREIA, 1998, p. 16; VIGEVANI; OLIVEIRA; CINTRA, 2003, p. 40; VIZENTINI, 2005, p. 389). O desempenho de FHC instrumentalizou de forma profunda a diplomacia presidencial com a finalidade de ganhar espaços nos processos de integração regional (MARTINS, 2006, p. 13). Desse modo, o Brasil ganhou protagonismo tanto no Mercosul como nas negociações da ALCA e NAFTA, no Tratado de Cooperação Amazônica, e com o apoio ao conflito do Cenepa, consolidou-se como um aliado pacífico na região, preocupado com a paz sul-americana, a cooperação militar e o combate às ameaças transnacionais (BIATO, 1999, p. 246).

A resolução do conflito do Cenepa teve como marco a solicitação de uma arbitragem $^{19}$ por parte dos países em confronto para os Países Garantes, que emitiram uma resolução obrigatória no marco do Protocolo de Rio de Janeiro. Isto é, seguiu-se o documento Reflexiones, modificando alguns pontos que beneficiariam ao Equador, como a doação de um $\mathrm{km}^{2}$ na região de Tiwintza por parte do Peru ao Equador (ACTA PRESIDENCIAL DE BRASILIA, 1998).

Em termos de segurança internacional é importante destacar que o principal instrumento para o destaque da participação do Brasil foi o acionamento da MOMEP como uma operação de manutenção da paz. Mesmo não se desenvolvendo nas margens internas da ONU, esse tipo de operação é reconhecido como uma tarefa com características onusiana (PÉNDOLA, 2005, p. 74; VALDIVIESO, 2015, p. 222).

$\mathrm{Na}$ administração de FHC, a preocupação com política internacional, como foi argumentando anteriormente, debruçou-se com relação a uma atuação moderada no âmbito global. A ONU foi a plataforma que permitiu a inserção brasileira através das

${ }^{17}$ O jornal Folha de São Paulo recupera algumas intervenções de FHC como principal ator da política externa, mostrando que sua marca foi manter uma diplomacia ativa na América Latina (FOLHA DE SÃO PAULO, 1998a; 1998b).

${ }^{18}$ O Plano Real foi um método de estabilização económica que substituiu a moeda cruzeiro pelo Real e conteve a superinflação. Para saber mais ver (OLIVEIRA; TUROLLA, 2003).

${ }^{19}$ A diferença entre mediação e arbitragem radica em que aquele instrumento favorece ao diálogo sugerindo alternativas. A arbitragem, por seu lado, emite ações vinculantes que as partes devem respeitar sem questionar. Para saber mais ver (MANZUR, 2014). 
operações de paz. Como pode ser evidenciado no Gráfico 1, o Brasil teve um impulso de participação nas missões de paz entre 1994 e 1998. A colaboração máxima, na década de 1990, é registrada no ano de 1996, quando o país participou na UNAVEM III ${ }^{20} \mathrm{em}$ Angola.

Gráfico 1. Médias anuais de participação brasileira em OP (1990-2018*)

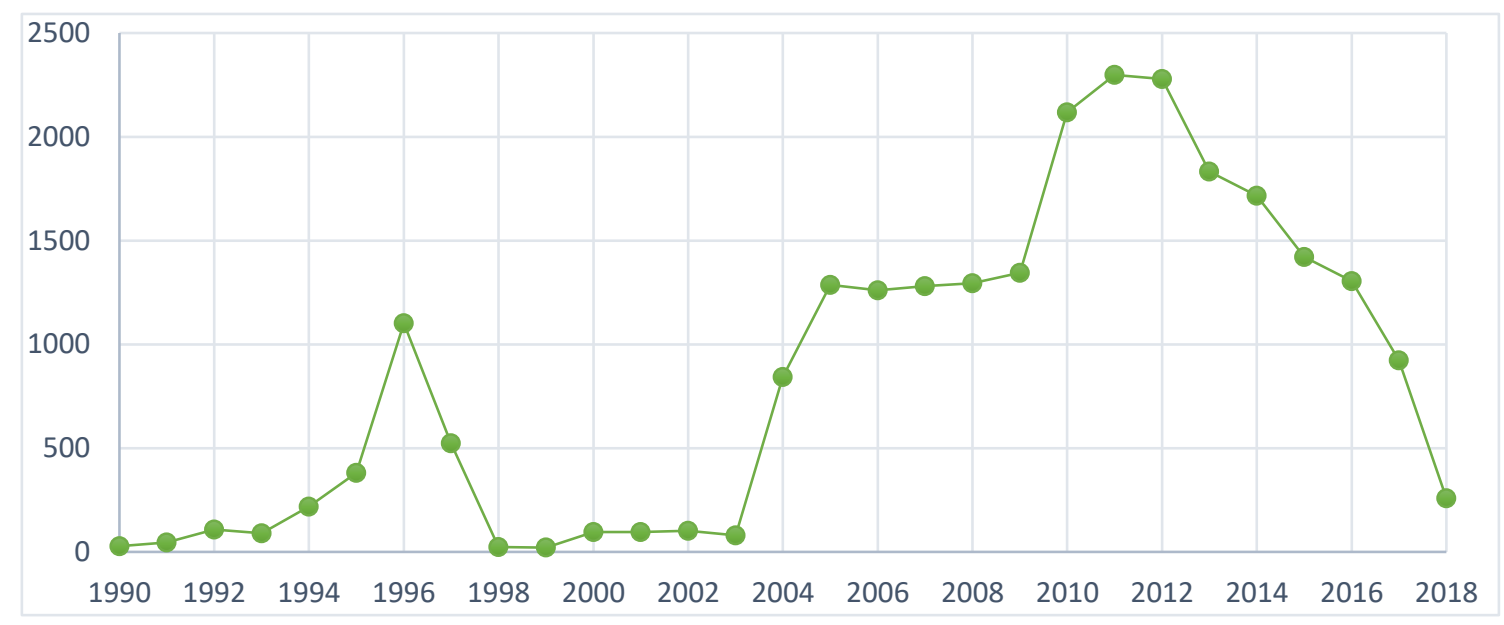

Fuente: elaboração própria com base em DPKO (2018). *Dados coletados até março de 2018.

Para Paulo Roberto de Almeida, diplomata brasileiro, as medidas estabelecidas por FHC na política externa se concentraram no estabelecimento de uma liderança limitada para a região (ALMEIDA, 2004, p. 13). Portanto, uma atuação localizada em problemas específicos da vizinhança, como o ocorrido entre Equador e Peru, formou parte da estratégia de política externa brasileira pertinente para as circunstâncias. Pois, foi a atuação das tropas brasileiras a que "fiscalizaram a região do conflito, evitando a possível retomada às armas" (FARIAS, 2011, p. 260). O país líder participou com 191 militares e colaborou com "viaturas, motoristas e equipes de manutenção para deslocamento diário nas estradas [...] equipamento de geração de energia elétrica para as sedes da missão [...] contava ainda com voos mensais de aeronaves Hércules e Bandeirantes da FAB" (EXÉRCITO BRASILEIRO, 2018; GALASTRI, 2005, p. 53). Por tanto, o Brasil depositou grandes recursos na superação do confronto territorial entre Equador e Peru, o que favoreceu a sua imagem de gerenciador efetivo de problemas da região.

${ }^{20}$ La contribución brasileña en Angola llevó al país a tener la cuarta posición entre los 10 mayores colaboradores (NACIONES UNIDAS, 2018). 


\section{Considerações finais}

$\mathrm{O}$ artigo teve a finalidade de refletir sobre as medidas adotadas pela política externa brasileira, no exercício diplomático, com relação ao conflito entre Equador e Peru. Foram formuladas duas perguntas que guiaram o raciocínio e a análise do trabalho, sendo estas: quais foram os principais atores da diplomacia brasileira que acompanharam a superação do conflito? Que mecanismos foram pensados e empregados pela política externa brasileira para a resolução do problema de fronteiras?

No marco da primeira questão, considera-se importante destacar a presença brasileira, desde o tratado de 1942, já que a elaboração desse protocolo permitiu que o país assumisse uma responsabilidade de caráter regional e futuramente, em 1995, liderasse a primeira operação de manutenção da paz na América do Sul: a MOMEP. Destaca-se também a atuação diplomática de figuras como Oswaldo Aranha, na década de 1940, e de Luiz Felipe Lampreia e Fernando Henrique Cardoso, na década de 1990.

Com relação ao segundo questionamento, o instrumento de política externa denominada "diplomacia presidencial" foi a base de apoio tanto em temas relativos ao conflito, como fora dele. Mas, com relação à disputa territorial, a diplomacia presidencial favoreceu a uma postura brasileira de imparcialidade e busca de benefício comum. A implementação da MOMEP foi uma iniciativa bem acolhida pela sociedade internacional por ser um recurso fundamental na consolidação da paz e por abrir caminhos para a negociação entre as partes.

Resta indicar que a política externa brasileira operacionalizou de modo adequado o recurso da negociação inserindo aos Países Garantes, liderados pelo Brasil, nessa fundamental tarefa de abrir caminhos apropriados para os diálogos de paz. Não obstante, para obter o resultado esperado teve que derivar em um outro processo conhecido como arbitragem, que foi acionado pela carta dos presidentes.

\section{Referências bibliográficas}

ACTA PRESIDENCIAL DE BRASILIA. Brasília, 1998

ACUERDO DE SANTIAGO, Santiago de Chile, 1996.

ALMEIDA, Paulo. Um exercício comparativo de política externa: FHC e Lula em perspectiva. Meridiano 47- Journal of Global Studies, v. 5, n. 42-43, p. 11-15, 2004. 
Disponível em: <http://periodicos.unb.br/index.php/MED/article/view/4258/3568> . Acceso em: 10 jun. 2018.

ARRAES, Virgílio. O Brasil e o Conselho de Segurança da Organização das Nações Unidas: dos anos 90 a 2002. Revista Brasileira de Política Internacional, v. 48, n. 2, p. 152-168. 2005. Disponível em: 〈http://www.scielo.br/pdf/rbpi/v48n2/a08v48n2.pdf >. Acceso em: 10 jan. 2018.

BATISTA, Nilton José. A participação do Brasil no processo de paz Equador-Peru. 2005.

BIATO, Marcel. “O processo de paz Peru-Equador”. Parcerias Estratégicas, n. 6, p. 241-247. $1999 . \quad$ Disponível em: <http://seer.cgee.org.br/index.php/parcerias_estrategicas/article/viewFile/62/54>. Acceso em: 10 jan. 2018.

BLANCO, Jaqueline. "De la Gran Colombia a la nueva Granada, contexto históricopolítico de la transición constitucional”. Revista Prolegómenos Derechos y Valores, v. 10, n. 20, p. 71-87. 2007. Disponível em: <http://www.unimilitar.edu.co/documents/63968/72398/04.GranColANvaGranada.pdf> . Acesso em: 15 jan. 2018.

CARRIÓN, Francisco. La Paz por Dentro: Ecuador-Perú: testimonio de una negociación. Quito: Dinediciones, 2008. Disponível em: <http://www.flacsoandes.edu.ec/libros/110278-opac>. Acesso em: 15 jan. 2018.

CARTA DE LOS PRESIDENTES. Carta que dirigen los Presidentes Jamil Mahuad y Alberto Fujimori al Presidente Fernando Henrique Cardoso. Brasilia, 1998.

CERVO, Amado Luiz. "Relações Internacionais do Brasil: um balanço da era Cardoso". Revista Brasileira de Política Internacional. v. 45, n. 1, p. 5-35. 2002. Disponível em: <http://www.scielo.br/scielo.php?script=sci_arttext\&pid=S0034-73292002000100001>. Acesso em: 10 jan. 2018.

CRUZ, Sergio (Coord.) Brasil em Missões de Paz. São Paulo: 2005.

DECLARACIÓN DE PAZ DE ITAMARATY ENTRE ECUADOR Y PERÚ. Brasília, 1995.

EXÉRCITO BRASILEIRO. Exército em ação: MOMEP. Disponível em: < http://www.eb.mil.br/momep>. Acesso em: 10 jun. 2018.

FARIAS, Tamara. A sul-americanidade da política externa brasileira no Governo de Fernando Henrique Cardoso. Universitas Relações Internacionais, v. 9, n. 7, p. 247272, 2011. Disponível em: <https://www.publicacoesacademicas.uniceub.br/relacoesinternacionais/article/view/13 79>. Acesso em: 10 jun. 2018. 
FGV. Fundação Getúlio Vargas. E ele voltou... o Brasil no segundo governo Vargas. 2018.

Disponível

em:

<http://cpdoc.fgv.br/producao/dossies/AEraVargas2/artigos/EleVoltou/ComissaoMista> . Acesso em: 10 jan. 2018.

FOLHA DE SÃO PAULO. Brasil intensifica diplomacia. Disponível em: <https://www1.folha.uol.com.br/fsp/mundo/ft02069803.htm>. Acesso em: 10 jun. 2018. Peru e Equador selam acordo de paz. Disponível em: <https://www1.folha.uol.com.br/fsp/mundo/ft27109808.htm>. Acesso em: 10 jun. 2018.

FONSECA, Carmen. A política externa brasileira da democracia: o paradoxo da mudança na continuidade? Relações Internacionais, n. 29, p. 33-43, 2011. Disponível em: <http://www.scielo.mec.pt/pdf/ri/n29/n29a03.pdf >. Acesso em: 10 jun. 2018.

GALASTRI, Leandro. La Misión de Observadores Militares Ecuador-Perú - MOMEP (1995-1999) y la Participación del Ejército Brasileño. 2005. 141 páginas. Disertación (Maestría en Ciencia Política) - Universidad Estadual de Campinas - Campinas.

IZURIETA, Galo. Un Protocolo Inejecutable. In: ANDRADE, David. Victoria en el Cenepa. Quito: Instituto Geográfico Militar, 2011.

KRIEG, Willian, Ecuadoran-Peruvian Rivalry in the Upper Amazon, 2d ed. Washington D.C.: Department of State, 1986.

LACERDA, Jan; NÓBREGA, Mariana. A política externa brasileira e o paradigma institucionalista pragmático: o âmbito político-institucional dos BRICS. Revista de Estudos Internacionais. V. 6 (n. 1), p. 126-147, 2015. Disponível em: <http://www.revistadeestudosinternacionais.com/uepb/index.php/rei/article/view/166>. Acesso em: 10 jan. 2018.

LAMPREIA, Luiz Felipe. "A política externa do governo FHC: continuidade e renovação". Revista Brasileira de Política Internacional, v. 42, n. 2, p. 5-17. 1998. Disponível em: <http://www.scielo.br/scielo.php?script=sci_abstract\&pid=S0034$73291998000200001 \& \operatorname{lng}=e n \& n r m=i s o \& t \operatorname{lng}=p t>$. Acesso em: 10 jan. 2018.

LIMA, Marcos Felipe. Do americanismo ao universalismo. As transformações nas Relações Internacionais do Brasil, de 1902 a 1964. 2006. 122 páginas. Dissertação (Mestrado em Relações Internacionais) - Universidade de Brasília - Brasília. Disponível em:

<http://repositorio.unb.br/bitstream/10482/2227/1/2006_Marcos\%20Felipe\%20Pinheiro $\% 20$ Lima.pdf $>$. Acesso em: 10 jan. 2018.

LIMA, Maria Regina. Ejes analíticos y conflicto de paradigmas en la política exterior brasileña. América Latina/Internacional-FLACSO/Argentina, v. 1, n. 2, p. 26-46, 1994. 
LOPEZ, Ernesto. Nova problemática de segurança e "novas ameaças". In: Novas Ameaças: Dimensões e Perspectivas. Desafios para a cooperação em defesa entre Brasil e Argentina. São Paulo: Sicurezza, 2003.

MANZUR, Tânia. Negociações Internacionais. São Paulo: Saraiva, 2014.

MARCELLA, Gabriel. Guerra y Paz en el Amazonas: Implicancias políticas del conflicto Ecuador-Perú para los Estados Unidos y América Latina. In: CHÁVEZ, Armando. El Perú y sus fronteras geopolíticas, tensiones territoriales y guerra con Ecuador. Lima, 2000. Disponible en: <http://fr.calameo.com/read/00011609309c0d5de6350>. Acesso em: 17 jan. 2018.

MARES, David; PALMER, Scott. Poder, instituciones y liderazgo en la paz y la guerra. Aprendizajes de Perú y Ecuador (1995-1998). Quito: FLACSO, 2012.

MARTINS, Fernanda. Política Externa no Governo do Presidente Fernando Henrique Cardoso: a articulação regional e a integração Sul-Americana (1995-2002). 2006. 214 páginas. Dissertação (Mestrado em História) - UFRGS - Porto Alegre. Disponível em: <http://www.funag.gov.br/ipri/btd/index.php/10-dissertacoes/747-apolitica-externa-no-governo-do-presidente-fernando-henrique-cardoso-a-articulacaoregional-e-a-integracao-sul-americana-1995-2002>. Acesso em: 10 jan. 2018.

MELLO, Eduardo. Democracia, Democratização e Política externa: Um estudo sobre a formulação da política de segurança no Brasil (1985-2002). 2010. 188 páginas. Dissertação (Mestrado em Relações Internacionais) - PUC/Rio de Janeiro - Rio de Janeiro. Disponível em: <https://www.maxwell.vrac.puc-rio.br/18314/18314_1.PDF>. Acesso em: 10 jan. 2018.

MELLO, Flavia de Campos. "Política Externa Brasileira e os Blocos Internacionais". São Paulo em Perspectiva, v. 16, n. 1, p. 37-43. 2002. Disponível em: <http://www.scielo.br/scielo.php?script=sci_arttext\&pid=S0102-88392002000100005>. Acesso em: 10 jan. 2018.

MINISTÉRIO da Defesa. Exército em Ação. 2018. Disponível em: <http://www.eb.mil.br/unavem>. Acesso em: 10 jan. 2018.

MINISTÉRIO Relações Exteriores. Zona de Paz e Cooperação do Atlântico Sul. 2018. Disponível em: <http://www.itamaraty.gov.br/pt-BR/politica-externa/paz-e-segurancainternacionais/151-zona-de-paz-e-cooperacao-do-atlantico-sul>. Acesso em: 10 jan. 2018.

MIYAMOTO, Shiguenoli. A Política Externa Brasileira e as Operações de Paz. Revista Brasileira de Estudos Políticos, v. 98, p. 361-394. 2008. Disponível em: <http://www.pos.direito.ufmg.br/rbep/index.php/rbep/article/view/79>. Acesso em: 10 jan. 2018. 
MONCAYO, Paco. Cenepa: Antecedentes, el conflicto y la paz. Quito: Editora Nacional, 2011.

MOREIRA; QUINTEROS; SILVA. As relações internacionais da América Latina. Petrópolis: Vozes, 2010.

NACIONES UNIDAS. Troop and police contributors. 2018. Disponible en: <https://peacekeeping.un.org/sites/default/files/jun-1996.pdf>. Acceso en: 11 mayo 2018.

NOVAK, F.; NAMIHAS, S. Perú-Ecuador: una experiencia exitosa de paz y buena vecindad. Lima: Konrad Adenauer Stiftung-Instituto de Estudios Internacionales (IDEI), 2010. Disponível em: < http://idei.pucp.edu.pe/libros/2010-serie-pexp-peruecuador.pdf>. Acesso em: 10 jan. 2018.

OLIVEIRA, Genser; TUROLLA, Frederico. "Política econômica do segundo governo FHC: mudança em condições adversas". Tempo Social, v. 15, n .2, p. 195-217. 2003. Disponível em: < http://www.scielo.br/pdf/ts/v15n2/a08v15n2>. Acesso em: 22 jan. 2018.

ORTEGA, Deila. O "Protocolo do Rio de Janeiro": Sua hermenêutica jurídica face ao Direito de Integração. Revista Ética e Filosofia Política, v. 1, n. 13, p. 96-121. 2011. Disponível em: <http://www.ufjf.br/eticaefilosofia/files/2011/01/13_1_deila.pdf>. Acesso em: 22 jan. 2018.

PÁEZ, Rodrigo. "El proceso de negociación del Grupo de Contadora". SRE-Revista Mexicana de Política Exterior. (N. especial), p. 63-74. 2013. Disponível em: <https://revistadigital.sre.gob.mx/index.php/numeros-anteriores/155-rmpe-ne2013>. Acesso em: 10 jan. 2018.

PÉNDOLA, Marcelo. Chile y las operaciones de paz: de la participación individual a Haití. Revista Fuerzas Armadas y Sociedad, v. 19, n. 1, p. 73-84, 2005. Disponible en: <http://www.fes-seguridadregional.org/images/stories/docs/0359-001_g.pdf>. Acceso em: 17 mayo 2018.

PÉREZ, Jorge. Tesis de Nulidad e Inejecutabilidad- el Arbitraje Papal. In: JIMÉNEZ, Gloria. Ecuador y Perú: ¿Futuro de paz? Quito: La Bunga, 1992.

PRADO, Julio. La propuesta arbitral. In: JIMÉNEZ, Gloria. Ecuador y Perú: ¿Futuro de paz? Quito: La Bunga, 1993.

PROTOCOLO DE PAZ, AMISTAD Y LÍMITES ENRE EL ECUADOR Y PERÚ. Rio de Janeiro, 1942.

RECASENS, Rafael. "Misión de Observadores Militares Ecuador-Perú (MOMEP). Experiencia de la participación de Chile”. Revista de Marina., v. 5, p. 01-12, 2000. 
Disponível em: <http://revistamarina.cl/revistas/2000/5/recasens.pdf>. Acesso em: 22 jan. 2018.

ROLDÓS, Jaime. Discurso de Jaime Roldós Aguilera 24 de mayo de 1981. Quito, 1981. Disponível em: <https://es.wikisource.org/wiki/Discurso_de_Jaime_Rold\%C3\%B3s_Aguilera_en_el_E stadio_Ol\%C3\%ADmpico_Atahualpa_(24_de_mayo_de_1981)>. Acesso em: 22 jan. 2018

ROJAS-ARAVENA, Francisco. América Latina. El difícil cambio de la concertación y la integración. Nueva Sociedad, v. 125, p. 1-12. 1993. Disponível em: $<$ http://nuso.org/articulo/america-latina-el-dificil-cambio-de-la-concertacion-y-laintegracion/>. Acesso em: 10 jan. 2018.

SARAIVA, Miriam; VALENÇA, Marcelo. A Política Externa Brasileira e sua Projeção Internacional: um projeto caracterizado pela continuidade. CEBRI, v. 1, p. 1-32. 2012. Disponível em: <http://midias.cebri.org/arquivo/pol_ext_br_proj_int.pdf>. Acesso em: 10 jan. 2018.

VALDIVIESO, Cristian. El Conflicto Del Cenepa: Su Camino Hacia La Paz. Conjuntura Global, v. 4, n. 2, p. 221-235, 2015. Disponível em: $<$ http://www.humanas.ufpr.br/portal/conjunturaglobal/files/2016/02/9-El-Conflicto-DelCenepa-Su-Camino-Hacia-La-Paz.pdf > . Acesso em: 10 jan. 2018.

VALENCIA, Luis. Antecedentes históricos del problema limítrofe. In: JIMÉNEZ, Gloria. Ecuador y Perú: ¿Futuro de paz? Quito: La Bunga, 1993.

VIGEVANI; OLIVERIA; CINTRA. Política externa no período FHC: a busca da autonomia pela integração. Tempo Social, v. 15, n .2, p. 31-61. 2003. Disponível em: <http://www.scielo.br/scielo.php?script=sci_arttext\&pid=S0103-20702003000200003>. Acesso em: 10 jan. 2018.

VIZENTINI, Paulo. “O Brasil e o Mundo: a política externa e suas fases”. Ensaios FEE, v. 20, n. 1, p. 134-154. 1999. Disponível em: <https://revistas.fee.tche.br/index.php/ensaios/article/view/1941>. Acesso em: 10 jan. 2018 .

. De FHC a Lula. Uma década de política externa (1995-2005). Civitas

- Revista de Ciências Sociais, v. 5, n. 2, p. 381-397. 2005. Disponível em: <http://revistaseletronicas.pucrs.br/ojs/index.php/civitas/article/view/9/1602〉. Acesso em: 10 jan. 2018.

Recebido em: Abril de 2018

Aprovado em: Julho de 2018 